\title{
Myanmar Secondary School EFL Teachers' Perceptions on the Use of English as a Medium of Instruction in Their EFL Teaching
}

\author{
Thawdar Lwin ${ }^{1 *}$ Aaron Richards ${ }^{2}$ \\ 1. Faculty of Education, Northeast Normal University, 5268 Renmin Street, Changchun City, Post Code: \\ 130024, Jilin Province, China. \\ 2. Language Centre, Xi'an Jiaotong-Liverpool University, 111 Ren'ai Road, Suzhou, Jiangsu, China
}

\begin{abstract}
This qualitative study was to examine the Myanmar secondary school English as a foreign language (EFL) teachers' perceptions on the use of English as a medium of instruction in their EFL teaching. A semi-structured interview was conducted with six secondary school EFL teachers (five female and one male). The findings and the results from the interviews showed that the language policy of using English as a medium of instruction in teaching English at the upper secondary level was not implemented by Myanmar EFL teachers. The availability of teaching materials such as textbooks and teaching aids, the teachers' inadequate knowledge for using English as a medium of instruction in class, students' poor language proficiency level and the assessment system were explored as the major factors for not being able to foster English as a medium of instruction in class.
\end{abstract}

Keywords: English as a medium of instruction, EFL teachers' perception

DOI: $10.7176 / \mathrm{JEP} / 10-6-17$

\section{Background of the study}

English as a medium of instruction (EMI) refers to the use of English language in teaching a subject, especially in the places where English is not the native, local or national language (Madhavan \& McDonald, 2014). With the rapid growth of the role of English in an era of internationalization, studies and research conducted on the development of EMI have gained interest in the field of second/foreign language education. Studies done on the use of EMI aimed to investigate the factors influencing the implementation of EMI in real classroom teaching, the teachers and students' perceptions on the use of EMI in class, the views of curriculum developers and the universities. Pedagogically, the idea of using EMI in English teaching has received positive criticism by language practitioners and researchers in that it creates more opportunities for learners to use the language by increasing the amount of exposure to the target language.

For example, Taylor (1975) stated that the influence of the learners' first language leads to low acquisition of the second language. Contrary to this, less influence of the first language resulted in more proficiency of the learners' second language. He proposed that this can be solved or reduced by the natural input of the target language. In a cross cultural study of Ransdell (2003), the researcher highlighted the three main reasons that caused Korean, Chinese, and Indian students' difficulty in learning English phonology. He described that the alphabetical shapes and the structures of students' mother tongue or the first language would cause interference while they are learning a second language. The second reason was less practices and fewer exercises in the target language provided by school teachers. The third reason was the medium of instruction. Most schools and colleges usually use their first language for communication or instruction in the classroom. As a result, students have less exposure to the practical use of the target language. Wong, a researcher who conducted a longitudinal action research study in one Hong Kong institute, concluded that students preferred the policy of using EMI and it also helped to improve students' English proficiency (Wong, 2009).

Nevertheless, the use of English language as a medium of instruction still has been hotly debated especially in countries where English is being taught and learnt as a foreign language. Vu and Burns (2014) explored the challenges of Vietnamese EFL teachers in implementing the policy of using EMI in a Vietnamese university. They highlighted the inadequate resources, teachers' abilities to use English in class, students' competency of English language and their learning styles as the main challenges. Another study about the implementation of EMI in India by Vulli (2014) illuminated the need of qualified, trained teachers as one of the important issues in implementing this policy. In a similar study of adopting EMI in Ghana by Owu-Ewic and Eshun (2015), the researchers concluded that the implementation of the policy of using EMI in Ghanaian junior high schools was 
still struggling with many issues such as teachers' preference of using students' native language in class, students' lack of competence the language, teachers' usual way of teaching English by grammar translation method and lack of support for the language policy.

Myanmar, like many Asian countries, has a similar problem in adopting a language for education and justifying it with the needs of the local context, including the economic, social and cultural situations of the country. Myanmar is a very diverse nation with eight majority ethnic groups and more than 100 ethnic minorities. Each group has its own culture and languages. Despite diverse language varieties, English language has been used as the only foreign language in schools since the colonial period (Pe, 1978). Ever since then, there have been many changes and developments in English language teaching in Myanmar. One of the significant changes occurred by the time the New Education Program (NEP) was initiated in 1981. This program stemmed from the results of a seminar on education that was held in 1979 and aimed to improve the quality of Myanmar education considering the important role of English language and the need of its expansion in the educational field. As a consequence, English was prescribed to be taught starting from kindergarten with the intention of the development of students' four language skills: reading, writing, speaking and listening. From 1981 onwards, English was also identified as a medium of instruction for teaching English as a foreign language (EFL) and other science subjects such as chemistry, physics and biology at the upper secondary level. In higher education, it became the medium of instruction for all majors and minors apart from Burmese (MOE, 2017a). Despite the introduction of this policy for over three decades, few studies have been done on its effectiveness or implementation in real EFL teaching and learning situations (Paw, 2010).

Therefore, this study attempts to investigate the extent to which this policy has affected current EFL teaching at secondary level. Specifically, this study aimed to explore Myanmar EFL teachers' perceptions on the use of English in their EFL teaching by answering the following research questions:

1. How do Myanmar EFL teachers perceive the policy of using EMI in teaching English at the upper secondary level?

2. What are the factors influencing the use of English as a medium of instruction in Myanmar secondary schools?

\section{Methodology}

This study adopted a qualitative method. The sample for this study consisted of six secondary school EFL teachers. The participants were selected through purposive sampling. Patton (1990) states that the use of purposive sampling helps to gather information-rich cases whose study will highlight the questions or issues under study. They were chosen based on three main criteria: the subject and the grade they teach in secondary schools, their pre-service trainings, and years of teaching experience. First of all, the researcher made some inquiries about the demographic data of some EFL teachers with the help of the researcher's friend who is currently a secondary school EFL teacher. Then, she personally approached the teachers, introduced the study and asked if they were willing to participate in it after signing relevant informed consent forms. Among eight EFL teachers that she approached, five EFL teachers showed their eagerness to take part in the study. All of them were female. As the researcher also wanted to see any difference between male and female teachers' views on the use of EMI, she searched for another two male teachers and invited them to take part in the study. Only one of them responded to participate. The participants were given a pseudonym (see Table 1).

Table 1. Participants' Profile

\begin{tabular}{|l|l|l|l|l|l|}
\hline No. & Teachers & Gender & Qualification & $\begin{array}{l}\text { EFL Teaching } \\
\text { Experience }\end{array}$ & $\begin{array}{l}\text { Currently teaching } \\
\text { classes }\end{array}$ \\
\hline 1 & Soe Soe & Female & BA, B.Ed. & 11 years & Grade $10 \& 11$ \\
\hline 2 & Nay Nay & Female & BA, B.Ed. & 11 years & Grade $10 \& 11$ \\
\hline 3 & Cherry & Female & BA, B.Ed. & 11 years & Grade $10 \& 11$ \\
\hline 4 & Marlar & Female & BA, B.Ed. & 11 years & Grade $10 \& 11$ \\
\hline 5 & Zaw & Male & B.Ed. & 3 years & Grade $10 \& 11$ \\
\hline 6 & Maw Maw & Female & M.Ed. & 8 years & Grade $10 \& 11$ \\
\hline
\end{tabular}




\subsection{Data collection method and procedure}

Semi-structured interviews were used as the main instrument to collect data. The interviews were conducted for two rounds. The objective of the first interview was to explore EFL teachers' perceptions regarding the use of EMI in the context of EFL teaching in Myanmar secondary schools. The participants were allowed to choose the place and convenient time for their interviews. All the interviews took place in the participants' selected location such as café or at their homes. The interview was conducted with each individual teacher in native language, Burmese, in order that the participants could share their ideas and feelings more openly and clearly with the researcher. Each interview lasted about 90 minutes and was recorded by voice recorder, then transcribed and translated into English. The second interview was conducted only after the transcripts from the first interview had been finished being transcribed. The interview transcripts were sent to the participants and asked if there was any information they wanted to add or remove. None of them made any changes to their transcripts.

\subsection{Data analysis}

Thematic analysis was applied to analyze the interview data. Clarke and Braun (2013) stated that thematic analysis is useful in identifying themes or patterns in the collected data. These themes developed from the important or interesting data used to describe an issue or address the main research question. The researcher first read the transcripts repeatedly by taking notes on some important facts or any idea came up while reading. Then, the data were initially coded by marking the words and coloring the lines which were interesting and important for the research. All these codes were written down in a separate sheet. Altogether 23 codes were organized and fitted together in groups. Each group was generally identified as a theme. Initially, eight themes appeared from the coding. They were reviewed again according to whether all the codes were relevant to each theme or not, and whether they should be grouped together and support their theme or not. After being reviewed and modified, four main themes emerged and each of them was given a name.

\section{Findings}

With respect to the use of English language as a medium of instruction in Myanmar secondary schools, all the participants stated in their interviews that they couldn't use English as the medium of instruction in their classroom. Despite the awareness of the language teaching policy and the beliefs of the effectiveness of using EMI in class, teachers highlighted many factors that hindered this policy. The findings from the data analysis resulted in four main themes: the availability of teaching materials, teachers' inadequate knowledge for EFL teaching, students' poor language proficiency level and the assessment system.

\subsection{The availability of teaching materials}

The first theme of this study was the teaching and learning materials designed for upholding the language policy, in other words, encouraging the use of EMI in class. Language teaching practitioners and researchers proposed that the resources such as curricula and materials for language teaching and learning are the challenges and supports for implementing a new language program in that they are required to foster and support the demands of the new program. In this study, these resources can be divided into two sub-themes: textbooks and insufficient teaching aids.

\subsubsection{Textbooks}

Hutchinson and Torres (1994) described that textbooks play a crucial role in effective teaching and learning as they provide the necessary information for teaching and learning process through readings, texts, explanations, and so on. Textbooks are not only a guideline for teachers. They also help students to learn things systematically and in an organized way (Harmer, 2007). While interviewing the participants concerning the resources that support for the use EMI in class, they considered the English textbooks for upper secondary level ill-suited to foster the current language policy. Zaw and Marlar thought that the teaching units in the prescribed textbooks were not designed for using EMI. They shared:

"I think the lessons in the current textbooks are more suitable with translation method since most of the reading passages are too long and some of them are difficult to explain in English. For instance, the two units in grade (9) textbook such as "A Fatherless Child" and "Circulation of the Blood". Some usages in "A Fatherless Child" are so old that we no longer use them nowadays. Of course, we should learn these usages and old-fashioned writing style but how can we explain such old usages in English? And they seem quite classic and boring for such young learners. In "The Circulation of the Blood", the reading passage consists of many medical terms and complicated ideas about how the heart works in our body. Even in Burmese translation, it has already taken time for students to understand the concept." (Zaw) 
"We're supposed to teach the lessons according to the fixed schedule set by the school. And most of the lessons in the textbooks are in the form of long reading passages along with grammar exercises. There are only a few lessons for speaking practice. Normally, we skip the speaking practice as we take more time to explain such a long paragraph by translating everything. The lessons in the textbook are not designed to advocate the language policy. That's why we cannot use English in class." (Marlar)

Cherry supported Zaw's idea by pointing out the relationship between the policy of using EMI and the relevant language teaching method to foster this policy.

"The use of EMI also depends on the textbook and the teaching method we are using now. We cannot use English language too much while explaining a long reading passage. Most contents in the textbooks are long and complicated enough. If we want our students to use the language properly, we'd better teach the lessons prepared for short conversation, short stories, etc., by using student-centered approach such as cooperative learning or communicative language teaching method. But it's really difficult to use EMI and to change our teaching methods when we are teaching such a long paragraph. Textbook is of most importance."

These above statements revealed that the English textbooks for upper secondary level were one of the reasons why teachers didn't use English in class. They also indicated that the Myanmar EFL teachers were not satisfied with the use of current English textbooks. Cherry and Marlar complained that the lessons and the long reading passages given in the textbooks drew them back to the use of translation method. Other teachers such as Zaw, Maw Maw and Soe Soe mentioned the need for prescribing more lessons on communication skills in the textbooks. They urged that the textbooks for upper secondary level focus on reading passages and grammar lessons with little speaking conversation practice. No specific lesson for listening skill is provided. Soe Soe also suggested that the textbooks should be improved with colorful pictures and more interesting topics. At the same time, teachers also put great stress on the inconsistency between the language teaching policy and the lessons given in the textbooks. Zaw even strongly commented that he would be unable to use EMI if he were to use these prescribed textbooks.

\subsubsection{Insufficient teaching aids}

The use of instructional media plays an important role in importing better instruction and improving the teaching and learning process, as instructional media are used to enable the learner to achieve the learning objectives engagingly and interestingly. When exploring more about the resources required for using English as a medium of instruction, further information about the requirement of teaching aids was revealed by the teachers. With regard to the use of teaching aids such as audio and visual materials, teachers explained as follows:

"We also need effective teaching aids for effective EFL teaching. For example, when I want my students to listen to the native speakers' conversation or reading, I need some audio tapes or recordings. As I'm not a native teacher, I, myself also need to practice my English. We don't have support like good reference books or audiovisual materials." (Zaw)

"We'd better provide our students with more teaching-learning materials and class activities in which they can practice their English or they are motivated to learn English better. These materials and activities may be short videos, audio clips or even short trips. By doing so, they can enjoy learning English and also get opportunities to use the language in practice. Now we're not given any specific teaching aids to apply in class except pictures and posters. Sometimes, I even use my own money to buy some teaching aids." (Cherry)

"We don't have necessary support to use EMI in class. The reference books such as teachers' workbook, dictionaries, and any other relevant books for our EFL teaching are not readily available in school. There are also few teaching aids. Throughout my teaching career, it's been only two years since I received my teachers' workbook. The school provides only the textbooks for grade 10 and 11 . I have to buy the rest of the reference books by myself. I even used my own exercise books from secondary school and some notes I got from my preservice training course." (Maw Maw)

"I have about 60 students in my class. I usually use pictures as my teaching aids. The school doesn't provide any teaching aids especially audio-visual materials which would be really helpful for improving our language skill. For instance, using some teaching aids such as cassettes, sound box, and projector would be of great help for us to use EMI when our class size is big. Even pictures or posters, - I'm supposed to find by myself and use them in class." (Nay Nay)

As mentioned above, there were few teaching and learning materials provided for both EFL teachers and students in their schools particularly for students' communication skills. Teachers expressed their willingness to use the teaching aids and make their EFL teaching more effective: - however, they all faced the same challenges 
of dealing with big class size and the lack of teaching-learning materials supported for using EMI.

\subsection{Teachers' inadequate knowledge of English communication skills}

According to Peter (1977), a thorough knowledge in a subject or a field can be regarded as a priority for teacher preparation. Conant (1963) proposed that if a teacher's knowledge is limited or he is uninformed, this can had a detrimental effect on his teaching. Jadama (2014) stated that a teacher's subject matter knowledge should outstrip the limits of the textbook and the curriculum they teach. In this study, most EFL teachers confessed in their interviews that they-themselves- had difficulty in using EMI in that their knowledge of English language was limited. Cherry and Nay Nay's comments depicted their dissatisfaction with their own English language skills:

"I think I am very good at teaching the lessons given in this textbook. I mean, I know how to train my students to do the given exercises according to marking scheme. But I have to confess that I am still weak in speaking, listening and any other general knowledge about English. My language skill really need to improve a lot." (Cherry)

"I believe I can teach a student to pass the exam. But I think I still need to try harder to become a professional English teacher. I still cannot speak English fluently and accurately. I often doubt my pronunciation as well. So, I cannot use English in class." (Nay Nay)

With respect to their limited knowledge of using English in class, teachers further complained about their preservice and in-service training courses. Apart from one teacher, Zaw, the rest of the EFL teachers complained that they lacked practice in using English in their pre-service and in-service trainings. Moreover, they mentioned that they were not recommended to use English in class although the educators or university teachers often used English throughout their training duration. Maw Maw commented on her own skills as follows:

“As I am a language teacher, of course, I prefer to use English in class. But honestly speaking, I don't think I can use it effectively as my speaking and listening skill are not that good. Practically, I was not trained it in it and I have never used it before over my teaching career. We also don't have enough time to try it. We also need to be motivated and well-trained to use English in class, otherwise, the teachers, themselves, - will not able to use it well."

Another different view of pre-service training for teaching communication skills was made by Zaw. Unlike any other teachers, Zaw mentioned that his university teachers used EMI in his pre-service training course. Though he enjoyed his EFL learning experiences in pre-service training, he found that it was still difficult to use English in class when he became a teacher. He explained:

"We had two teachers for students majoring in English language teaching. I preferred the one who taught language teaching methods. He used English as a medium of instruction but his English was simple, fluent and easy to understand. He had much knowledge about language teaching strategies. He did train us how to use teaching methods in class in practice. But he didn't train us to use English in class. Yes, he suggested it but I feel like we also need to be trained for this as well. We should use English in class, I agree with this. I prefer to use it as well. But it's impossible to use English now because we teachers, ourselves are not ready for it."

These above statements indicated that both pre-service and in-service training had influenced Myanmar EFL teachers' use of English in class. Teachers felt that these courses couldn't give a clear description of the English language teaching policy at the upper secondary level. Moreover, they thought they were not clearly instructed to use EMI in class. They were not trained to use EMI as well. They all expressed that what they had learnt in their training programs could not be effectively applied in their real teaching practices.

\subsection{Students' language proficiency level}

Students' poor language proficiency level was illuminated in all participants' statements while they were interviewed about the use of students' native language in class instead of English. The participants pointed out that the students' level was somehow related to the assessment system since many of their students passed their exams every year without comprehending the lessons properly.

"I think it'll be difficult to use EMI in my class. Most of my students are quite weak in listening and speaking skills. And the reason is clear: they have never used English before so they can't speak and listen to English at all. They have learned how to memorize things throughout their students' life without applying them. How can we make a dramatic change now? Even if we try to use EMI, they will not be able to understand the lesson. We also don't have enough time to explain until they understand it." (May)

"They used to pass the exam without trying hard. For example, let's say they are good at other subjects, but they 
fail in English. Then they still can pass the exam, you know. The assessment system is not effective enough to evaluate their performance. So, students can attend their Grade 10 class without knowing basic English. I have seen many students whose language proficiency is rather weak. They cannot even differentiate between "verb" and "noun", or "pronoun." Some students even have difficulty in learning Burmese literature." (Maw Maw)

"You know, I am the only one using English in class. My students may listen to me, they may understand what I am saying, but they seldom speak up and say something in English. They are not motivated to use English ever. As far as I remember, there was only one student who was eager to speak in English throughout my career. The main weakness of my students is incorrect pronunciation as they used to learn the meanings and pronunciation of the given words by heart. They don't know phonetics as well. Our EFL teaching focuses on reading skills, too much. But there are also many students who have difficulty in reading with correct pronunciation and intonation. Such students exist in almost every class although the classes are divided according to their exam results. I'm not blaming anyone but this is because they don't have basic knowledge that they should get in their primary level." (Zaw)

Generally speaking, Myanmar secondary EFL teachers considered their students' English language proficiency to be poor since most of them lacked a good basic knowledge of English that they should have learned in their primary and lower secondary level. They mentioned that their students were not good at all four language skills. First, this was because of the weakness of the language policy, itself. According to the language policy, students were supposed to learn English by not using their native language, Burmese, only at the upper secondary level. Teachers assumed that it was not that easy to switch the medium of instruction suddenly at this level since students were accustomed to learning English through the use of their native language over the course of their previous education. Secondly, the monthly tests, final examination and their grades were not reliable and effective in assessing their performances. As a consequence, students might be unaware of their weakness in English and their actual grade level or performance. Thirdly, students were not well-motivated to use English in class.

\subsection{Assessment system}

The last theme was the assessment system for EFL students currently used in the Myanmar secondary schools. Biggs and Tang (2011) stated the role of assessment for quality learning in that students learn what they think they will be tested on. In this study, the assessment system was revealed as one of the factors that has impact on the use of EMI in English teaching. All the upper secondary level students have to take four chapter end tests, one mid-term exam and a final exam in one academic year. The Grade 11 students have to take a matriculation examination at the end of their Grade 11. The participants felt the chapter end tests (CET) or monthly tests and the final exam held at the upper secondary level were not reliable enough to assess a student' actual performance of English learning. These tests are weak in that all the questions tested in the exams are extracted from the prescribed textbooks apart from essay and letter composition. The Myanmar EFL teachers highlighted that all the tests taken in grade 10 were based on the highly structured matriculation exam format. Moreover, they said that the tests and exams in upper secondary level did not encourage them to use English in class. For instance:

"I think the assessment system is necessary to refine as it cannot evaluate anything except students' memorization skill. If a student can learn the whole textbook by heart including the old questions, he or she can pass the exam with ease. The reason why we want to use EMI is to improve students' communication skills. But the tests and exams cannot effectively assess students' performance or language efficiency." (Zaw)

"Only reading and writing skills are tested in monthly tests and matriculation exam so that students are not motivated to learn their lessons in English. Students want to pass the exam, parents want their children to get good results in the exam, and we-teachers-also need to teach them to be able to sit well in the exam. So, we all want students' clear understanding of the lessons for the exam. So, we are not motivated to use English in class." (Maw Maw)

As far as the use of English in class, it was evident from the above statements that the assessment system was not effective in measuring students' communication skills. First, Myanmar EFL teachers used students' native language or Burmese in class for students' understanding. Later on, they realized that students also only cared about their exam instead of using the language. The following was what Cherry perceived about the monthly tests and the final exam.

"Normally, we have monthly tests and chapter end tests. Monthly tests are held once a month. Chapter end tests are held twice a year; in October and in December. Of course, students will not learn English if they don't need to take it in exam. But you know what? The problem now is they just only care about the exams. They learn English only for the exam, only to be able to sit well in the exam. So, these tests are helpful for them to learn in 
another way, but not in a correct way. We use Burmese not only for explaining the lessons but also for training them how to sit well in the exam. So, I cannot use English in class, and my students are not motivated for it, too."

According to her comments and other teachers' views on the assessment system, we could see that the tests or exams for EFL learning at the upper secondary level were limited to assessing students' reading and writing skills. This ineffective assessment system resulted in teachers' choice of language teaching method since teachers generally believed that the use of their native language and the grammar translation method could help students to be able to sit well in the exam.

\section{Discussion and Conclusion}

The main objective of this study was to examine to what extent the language policy has affected Myanmar EFL teachers' teaching from which it explored their perception on the use of English as the medium of instruction in class.

From the overall findings of the study or the themes identified in the Myanmar EFL teachers' interviews, it can be generally concluded that the English language policy for the upper secondary level had only little impact on the teachers' teaching. Most participants realized that they should follow this policy and expressed their willingness to use English in class. However, despite the current English language education policy and the positive perceptions on the use of English as the medium of instruction by Myanmar EFL teachers, they all admitted that they didn't use English in class. Four main reasons were summarized and discussed as their rationalization for not using English in class. First of all, it was found that the important resources such as textbooks were not well-designed and favored for using English as a medium of instruction. The teaching and learning materials required for using EMI were insufficient or not provided. This finding coincided with the finding of $\mathrm{Vu}$ and Burns (2014) in that the availability of teaching and learning materials was one of the constraints for implementing the EMI policy.

The second important factor was the Myanmar EFL teachers' ability to use the language in class. Despite the awareness of the language policy and the different training programs, all participants in this study admitted that they don't use EMI in class. The weakness of their pre-service and in-service training programs resulted in their inadequate knowledge of how to use English in class. This challenge was supported by the similar results of many other studies (Manh, 2012; Vu \& Burns, 2014; Vulli, 2014).

The third factor was the students' level or their readiness for using English in class. According to teachers' explanations in their interviews, it could be concluded that most students were not ready to learn in English. Students were used to learning English by translating into their native language until their upper secondary level. Their poor basic knowledge of English and low language proficiency caused both they and their EFL teachers to use the native language. Owu-Ewie and Eshun (2015) also showed a similar finding of students' incompetency of language in implementing EMI in Ghana. Belhiah and Elhami (2015) also interpreted in his study of implementing EMI in the Arabian Gulf that students' low proficiency in English was one of the important factors to be considered in implementing the EMI policy.

The last factor, the assessment system was found to be related to the students' level and was described by the teachers as an ineffective one for fostering the language teaching policy. Teachers complained that the assessment system resulted in students' low language proficiency as the tests and exams for upper secondary level were not effective enough in measuring students' actual performance in the target language. Teachers were supposed to teach the lessons so students could sit well in the exams rather than teaching them how to use the language in real situations. As a consequence of this unreliable assessment system, both teachers and students were not motivated to teach and learn in English.

Finally, this study showed that the language policy of using EMI was not practically implemented in the secondary school EFL teaching classrooms. Teachers still use their native language or Burmese as the medium of instruction for teaching English. By exploring the factors requiring consideration in adopting a language policy, this study suggests to implement a language policy that meet the needs of the local context in particular and the global trends of English education in general and take action on it. The findings also leave implications for policy makers of education, curriculum implementation and teacher education. Further studies should examine the students' perceptions of EMI as students are the recipients while teachers are the implementer of the new policy. A similar study should be quantitatively conducted with a considerable number of teachers and students so that the results and findings can be more reliable and generalizable. 


\section{References}

Belhiah, H., \& Elhami, M. (2015). English as a medium of instruction in the Gulf: When students and teachers speak. Language policy, 14, 3-23.

Biggs, J., \& Tang, C. (2011). Teaching for quality learning at university (4 ${ }^{\text {th }}$ Ed.). Open University Press, UK.

Chang, B-M. (2011). The roles of English language education in Asian context. Journal of Pan-Pacific Association of Applied Linguistics, 15(1), 191-206.

Clarke, V., \& Braun, V. (2013). Teaching thematic analysis: overcoming challenges and developing strategies for effective learning. The Psychologist, 26(2), 120-123.

Conant, J. (1963). The Education of American Teachers. New York: McGraw-Hill.

Harmer, J. (2007). The Practice of English Language Teaching. Edinburgh. Pearson Education Ltd.

Hutchinson, T., \& E. Tores. (1994). The Textbook as Agent of Change. ELT Journal Volume 48/4. Oxford University Press.

Jadama, L.M. (2014). Impact of subject matter knowledge of a teacher in teaching and learning process: Middle East and African Journal of Educational Research, 7.

Madhavan, D., \& McDonald, J. (2014). Webinar: English as medium of instruction (EMI): Philosophies and Policies. OECD Higher E

Manh, L. D. (2012). English as a medium of instruction in Asian Universities: The case of Vietnam. Language Education in Asia, 3(2), 263-267.

MOE (Ministry of Education). (2017a). Tasks of national educational policy commission. Report to Pyithaungsu Hluttaw (2/2017). The Government of the Republic of Myanmar.

Owu-Ewie, C., \& Eshun, E. S. (2015). The use of English as medium of instruction at the Upper Basic Level (Primary four to Junior High school) in Ghana: From theory to practice. Journal of education and practice, 6(3), 72-82.

Pe. O. (1978). Teaching English in the Basic Education System. Paper presented at the tenth anniversary of the Burma educational research Bureau seminar. Myanmar: Burma Educational Research Bureau. Unpublished paper.

Patton, M. (1990). Qualitative evaluation and research methods (pp. 169-186). Beverly Hills, CA: Sage.

Paw, J (2000). Current English Policy in Myanmar. Retrieved November 16, 2016 from http://bruneisprogramme.org/wp-content/uploads/2013-Forum-Publication-Complete.104-110.pdf.

Peters, R. S. (1977). Education and the education of teachers. London: Routledge and Kegan Paul.

Ransdell, S. (2003). The care and feeling of monolingual and bilingual University students in South Florida: Implications for assessment and training. Psycol. Learn. Teach. 3(2): 126-130.

Taylor, B. (1975). The use of overgeneralization and transfer learning strategies by elementary and intermediate students in ESL. Language Learning, 25, 73-107.

Vulli, D. (2014). English and medium of instruction: Dalit discourse in Indian education. Research Journal of Educational Sciences, 2 (2).

$\mathrm{Vu}$, N. T. T., \& B, A. (2014). English as a medium of instruction: Challenges for Vietnamese tertiary lectures. The Journal of Asia TEFL, 11(3), 1-31.

Wong, R. M. H. (2010). The effectiveness of using English as the sole medium of instruction in English classes: Student responses and improved proficiency. Porta Linguarum 13, 119-130. 